\title{
DYRK I A genetic variants are not linked to Alzheimer's disease in a Spanish case-control cohort
} José Luis Vázquez-Higuera1, Pascual Sánchez-Juan¹, Eloy RodríguezRodríguez ${ }^{1}$, Ignacio Mateo ${ }^{1}$, Ana Pozueta ${ }^{1}$, Ana Frank ${ }^{2}$, Isabel Sastre ${ }^{3}$, Fernando Valdivieso ${ }^{3}$, José Berciano ${ }^{1}$, María J Bullido ${ }^{3}$ and Onofre Combarros*1

\author{
Address: ${ }^{1}$ Neurology Service and CIBERNED, "Marqués de Valdecilla" University Hospital (University of Cantabria), Santander, Spain, ${ }^{2}$ Neurology \\ Service and CIBERNED, Hospital Universitario La Paz (UAM), Madrid, Spain and ${ }^{3}$ Molecular Biology Department and CIBERNED, Centro de \\ Biología Molecular Severo Ochoa (CSIC-UAM), Madrid, Spain \\ Email: José Luis Vázquez-Higuera - josevazquezhiguera@hotmail.com; Pascual Sánchez-Juan - psanchez@humv.es; Eloy Rodríguez- \\ Rodríguez - eloymrod@gmail.com; Ignacio Mateo - mateonacho@hotmail.com; Ana Pozueta - anapozueta@gmail.com; \\ Ana Frank - afrankg@gmail.com; Isabel Sastre - isastre@cbm.uam.es; Fernando Valdivieso - fvaldivieso@cbm.uam.es; \\ José Berciano - jaberciano@humv.es; María J Bullido - mjbullido@cbm.uam.es; Onofre Combarros* - combarro@unican.es \\ * Corresponding author
}

Published: 8 December 2009

BMC Medical Genetics 2009, 10:129 doi:10.1186/147I-2350-10-129

This article is available from: http://www.biomedcentral.com/I47/-2350/10/129

(c) 2009 Vázquez-Higuera et al; licensee BioMed Central Ltd.

This is an Open Access article distributed under the terms of the Creative Commons Attribution License (http://creativecommons.org/licenses/by/2.0), which permits unrestricted use, distribution, and reproduction in any medium, provided the original work is properly cited.
Received: 30 July 2009

Accepted: 8 December 2009

\begin{abstract}
Background: As dual-specificity tyrosine phosphorylation-regulated kinase IA (DYRKIA) has been implicated in the abnormal hyperphosphorylation of tau in Alzheimer's disease (AD) brain, and the development of neurofibrillary tangles, we examined the contribution of this gene to the susceptibility for AD.

Methods: We examined genetic variations of DYRKIA by genotyping haplotype tagging SNPs (htSNPs) (rs I I70I483, rs2835740, rs I I37600, rs283576I, rs2835762, rs2I54545 and rs8I32976) in a group of 634 Spanish AD cases and 733 controls.

Results: There were no differences in the genotypic, allelic or haplotypic distributions between cases and controls in the overall analysis or after stratification by APOE $\varepsilon 4$ allele.

Conclusion: Our negative findings in the Spanish population argue against the hypothesis that DYRK IA genetic variations are causally related to AD risk. Still, additional studies using different sets of patients and control subjects deserve further attention, since supporting evidence for association between DYRKIA gene and AD risk in the Japanese population exists.
\end{abstract}

\section{Background}

Abnormal tau hyperphosphorylation has been suggested as being one of the central events in the development of neurofibrillary tangles (NFTs), which are one of the characteristic neuropathological lesions found in Alzheimer's disease (AD) brains [1]. Dual-specificity tyrosine phos- phorylation-regulated kinase 1A (DYRK1A) phosphorylates tau in vitro at the Thr212 residue [2], which is hyperphosphorylated in AD brains, and a significant increase in the amount of phosphor-Thr212-tau is also found in the brains of transgenic mice that overexpress human DYRK1A [3]. In addition, transgenic mice bearing 
a triple tau mutation and expressing hyperphosphorylated tau in neurons of the hippocampus and neocortex show increased expression of DYRK1A in individual neurons in the same regions [4]. Moreover, DYRK1A accumulates in NFTs in brains of subjects with sporadic $A D$ and in subjects with trisomy of chromosome 21 and Down syndrome (DS) [5]. The increase dosage of DYRK1A in DS brain due to trisomy of chromosome 21 correlates to an increase in three microtubule-binding domain repeats-tau level [6], which on abnormal hyperphosphorylation and aggregation of tau results in neurofibrillary degeneration [7]. All this data postulates a role for DYRK1A as an interesting genetic target for association analysis of $\mathrm{AD}$. Although genetic markers of the DYRK1A region were not found associated to $\mathrm{AD}$ in recent genome-wide association studies [8-11], Kimura et al. [12] scanned througt chromosome 21 to assess genetic associations with lateonset $\mathrm{AD}$ and found that DYRK1A showed the highest significant association with $\mathrm{AD}$ risk in the Japanese population. In addition, these authors suggested that DYRK1A could be a key molecule bridging between $\beta$-amyloid production and tau phosphorylation in $\mathrm{AD}$ [12]. In this report we sought to replicate this genetic association in the Spanish population.

\section{Methods}

The study included 634 AD patients (65\% women; mean age at study 75.9 years; SD 8.0; range 61-109 years; mean age at onset 72.8 years; SD 7.9; range 60-108 years) who met NINCDS/ADRDA criteria for probable AD [13]. All $\mathrm{AD}$ cases were defined as sporadic because their family history did not mention any first-degree relative with dementia. AD patients were recruited from the Departments of Neurology of University Hospital "Marqués de Valdecilla" (Santander, Spain), and Hospital "La Paz" (Madrid, Spain). The large majority of patients were living in the community and had been referred by their general practitioner; few had been admitted from hospital wards or nursing home facilities. Control subjects were 733 unrelated individuals ( $65 \%$ women; mean age 78.7 years; SD 9.4; range 60-104 years) randomly selected from nursing homes. These subjects had complete neurologic and medical examinations that showed that they were free of significant illness and had Mini Mental State Examination scores of 28 or more (corrected for age), which were verified by at least one subsequent annual following-up assessment. The controls arose from the same base population as the cases. The AD and control samples were Caucasians originating from a limited geographical area in northern Spain (Santander) and from the central area of Spain (Madrid).

Blood samples were taken after written informed consent had been obtained from the subjects or their representatives. The study was approved by the ethical committees of the University Hospital "Marqués de Valdecilla" and the Hospital "La Paz". Genotyping of DYRK1A (rs11701483, rs2835740, rs1137600, rs2835761, rs2835762, rs2154545 and rs8132976) polymorphism was performed by a Taq-Man single-nucleotide-polymorphism assay (Applied Biosystems, Warrington, Cheshire, UK) and an ABI PRISM 7000 or 7900HT sequence detection systems (Applied Biosystems). We used data from the HapMap project http://www.hapmap.org to select the 7 htSNPs capturing $86 \%$ of DYRK1A genetic variability in Caucasians. SNPs were chosen among those with minor allele frequencies $\geq 5 \%$ using Haploview v3.2 software http://www.broad.mit.edu/mpg/haploview with an $\mathrm{r}^{2}$ threshold of 0.8. The location of SNPs in DYRK1A gene used in the present study is described in Figure 1. APOE genotyping was performed by amplification of the 4th exon of the APOE gene by PCR with biotinylated primers, followed by reverse hybridization on nitrocellulose strips, using the INNO-LIPA ApoE assay (Innogenetics NV, Ghent, Belgium), or by HhaI restriction analysis.

Hardy-Weinberg equilibrium (HWE) was calculated for the $7 \mathrm{htSNPs}$ genotypes in the control population using Pearson's $\chi^{2}$ statistics. We assessed pairwise linkage disequilibrium (LD) between the $7 \mathrm{htSNPs}$ by $\mathrm{D}^{\prime}$ and $\mathrm{r}^{2}$ statistics. Haplotype reconstruction and their frequencies in cases and controls were estimated by an expectation-maximization algorithm. Pearson's $\chi^{2}$ statistics were performed to compare allele distribution of the patients and control for each htSNP. Haplotype frequencies were also assessed using Pearson's $\chi^{2}$ using Haploview 3.32 software

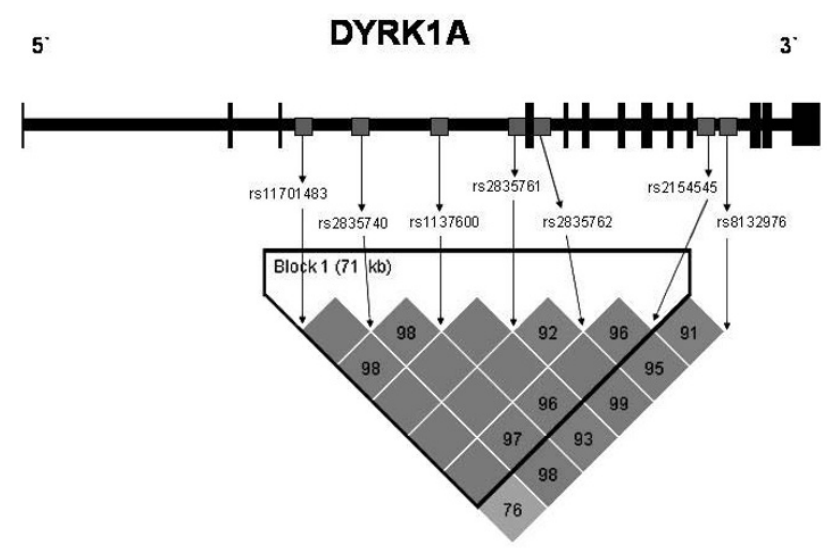

Figure I

Genomic structure and relative location of studied haplotype tagging SNPs (indicated by grey boxes) in the DYRKIA gene. Lines represent the introns between exons (black boxes). Pairwise linkage disequilibrium (LD) patterns between the $7 \mathrm{htSNPs}$ formed one haplotype block (numbers in box represent D' values, and the intensity of the color is proportional to the strength of the LD). 
http://www.broad.mit.edu/mpg/haploview. Rare haplotypes (total frequency $<0.05$ ) were excluded from the analysis.

\section{Results}

In control groups, no deviations from Hardy-Weinberg equilibrium were found for any of the $7 \mathrm{htSNPs}$. As shown in Table 1, the distribution of the allele and genotype frequencies of the DYRK1A htSNPs did not differ significantly between either un-stratified or APOE-stratified AD and control groups. Figure 1 shows the pattern of pair wise $\mathrm{LD}$, measured in terms of $\mathrm{D}^{\prime}$ coefficient, between the 7 chosen htSNPs. One block was found consisting of SNPs rs11701483, rs2835740, rs1137600, rs2835761, rs2835762 and rs2154545. When we estimated the haplotype frequencies in this haplotype block, we found that the haplotype distribution did not differ significantly between $\mathrm{AD}$ cases and controls (Table 2). There were no major differences in allele, genotype or haplotype frequencies of DYRK1A polymorphisms in our total sample associated to either age or gender subgroups (data not shown).

\section{Discussion}

In a series of 374 Japanese AD patients and 375 population-based controls, Kimura et al. [12] studied eight tagging SNPs (rs8126696, rs2251085, rs2835740, rs10470178, rs11701810, rs1024294, rs2835773 and rs2835774) located from $30 \mathrm{~kb}$ upstream of exon 1 to exon 13, observing a three times increased AD risk for carriers of the DYRK1A rs2835740 CC genotype (OR = 2.99, $95 \% \mathrm{CI}=1.72-5.19, \mathrm{p}=0.001)$, and haplotype analysis

Table I: Distribution of DYRKIA polymorphisms in patients and controls stratified by APOE $\varepsilon 4$ allele

\begin{tabular}{|c|c|c|c|c|c|c|c|}
\hline \multicolumn{2}{|c|}{ DYRKIA polymorphism } & \multicolumn{2}{|c|}{ APOE $\varepsilon 4$ allele noncarriers } & \multicolumn{2}{|c|}{ APOE $\varepsilon 4$ allele carriers } & \multicolumn{2}{|c|}{ Total sample } \\
\hline & & Patients & Controls & Patients & Controls & Patients & Controls \\
\hline \multirow[t]{5}{*}{ rsII70|483 } & AA & $226(0.78)$ & $486(0.79)$ & $273(0.83)$ & $85(0.74)$ & $499(0.81)$ & $57 \mid(0.79)$ \\
\hline & $A G$ & $58(0.20)$ & $119(0.20)$ & $54(0.16)$ & $27(0.24)$ & $112(0.18)$ & $146(0.20)$ \\
\hline & GG & $6(0.02)$ & $7(0.01)$ & $3(0.01)$ & $2(0.02)$ & $9(0.01)$ & $9(0.01)$ \\
\hline & Total & 290 & 612 & 330 & 114 & 620 & 726 \\
\hline & Allele frequency $A / G$ & $0.88 / 0.12$ & $0.89 / 0.11$ & $0.91 / 0.09$ & $0.86 / 0.14$ & $0.89 / 0.11$ & $0.89 / 0.11$ \\
\hline \multirow[t]{5}{*}{ rs2835740 } & TT & $187(0.65)$ & $366(0.62)$ & $217(0.66)$ & $74(0.66)$ & $404(0.66)$ & $440(0.62)$ \\
\hline & TC & $86(0.30)$ & $206(0.35)$ & $90(0.28)$ & $31(0.28)$ & $176(0.29)$ & $237(0.34)$ \\
\hline & CC & $13(0.05)$ & $24(0.04)$ & $19(0.06)$ & $7(0.06)$ & $32(0.05)$ & $31(0.04)$ \\
\hline & Total & 286 & 596 & 326 & 112 & 612 & 708 \\
\hline & Allele frequency $\mathrm{T} / \mathrm{C}$ & $0.80 / 0.20$ & $0.79 / 0.21$ & $0.80 / 0.20$ & $0.80 / 0.20$ & $0.80 / 0.20$ & $0.79 / 0.21$ \\
\hline \multirow[t]{5}{*}{ rsII37600 } & AA & $124(0.44)$ & $276(0.46)$ & $164(0.53)$ & $50(0.45)$ & $288(0.49)$ & $326(0.46)$ \\
\hline & $A G$ & $124(0.44)$ & $261(0.43)$ & $107(0.35)$ & $46(0.42)$ & $231(0.39)$ & $307(0.43)$ \\
\hline & GG & $32(0.12)$ & $69(0.11)$ & $37(0.12)$ & $14(0.13)$ & $69(0.12)$ & $83(0.12)$ \\
\hline & Total & 280 & 606 & 308 & 110 & 588 & 716 \\
\hline & Allele frequency $A / G$ & $0.62 / 0.38$ & $0.67 / 0.33$ & $0.71 / 0.29$ & $0.66 / 0.34$ & $0.69 / 0.31$ & $0.67 / 0.33$ \\
\hline \multirow[t]{5}{*}{ rs283576I } & $\mathrm{CC}$ & $203(0.70)$ & $422(0.69)$ & $232(0.72)$ & $84(0.75)$ & $435(0.7 I)$ & $506(0.70)$ \\
\hline & CT & $82(0.29)$ & $176(0.29)$ & $85(0.26)$ & $27(0.24)$ & $167(0.27)$ & $203(0.28)$ \\
\hline & TT & $4(0.01)$ & $\mathrm{II}(0.02)$ & $6(0.02)$ & $\mathrm{I}(0.01)$ & $10(0.02)$ & $12(0.02)$ \\
\hline & Total & 289 & 609 & 323 & 112 & 612 & 721 \\
\hline & Allele frequency $C / T$ & $0.84 / 0.16$ & $0.84 / 0.16$ & $0.85 / 0.15$ & $0.87 / 0.13$ & $0.85 / 0.15$ & $0.84 / 0.16$ \\
\hline \multirow[t]{5}{*}{ rs2835762 } & $\mathrm{CC}$ & $216(0.8 I)$ & $467(0.78)$ & $243(0.77)$ & $82(0.73)$ & $459(0.79)$ & $549(0.78)$ \\
\hline & CT & $49(0.18)$ & $119(0.20)$ & $69(0.22)$ & $27(0.24)$ & $118(0.20)$ & $146(0.21)$ \\
\hline & TT & $3(0.01)$ & $9(0.02)$ & $4(0.01)$ & $3(0.03)$ & $7(0.01)$ & $12(0.01)$ \\
\hline & Total & 268 & 595 & 316 & 112 & 584 & 707 \\
\hline & Allele frequency $\mathrm{C} / \mathrm{T}$ & $0.90 / 0.10$ & $0.88 / 0.12$ & $0.88 / 0.12$ & $0.85 / 0.15$ & $0.89 / 0.11$ & $0.88 / 0.12$ \\
\hline \multirow[t]{5}{*}{ rs2I54545 } & GG & $105(0.37)$ & $218(0.36)$ & $|4|(0.43)$ & $43(0.38)$ & $246(0.40)$ & $261(0.36)$ \\
\hline & GA & $136(0.47)$ & $280(0.46)$ & $135(0.42)$ & $49(0.44)$ & $271(0.44)$ & $329(0.46)$ \\
\hline & $\mathrm{AA}$ & $45(0.16)$ & $108(0.18)$ & $50(0.15)$ & $20(0.18)$ & $95(0.16)$ & $128(0.18)$ \\
\hline & Total & 286 & 606 & 326 & 112 & 612 & 718 \\
\hline & Allele frequency $G / A$ & $0.60 / 0.40$ & $0.59 / 0.41$ & $0.64 / 0.36$ & $0.60 / 0.40$ & $0.62 / 0.38$ & $0.59 / 0.41$ \\
\hline \multirow[t]{5}{*}{ rs8132976 } & $A A$ & $95(0.34)$ & $194(0.33)$ & $93(0.29)$ & $33(0.30)$ & I $88(0.3 \mid)$ & $227(0.32)$ \\
\hline & $A C$ & $122(0.43)$ & $285(0.48)$ & $138(0.43)$ & $48(0.43)$ & $260(0.43)$ & $333(0.47)$ \\
\hline & $\mathrm{CC}$ & $66(0.23)$ & $116(0.19)$ & $91(0.28)$ & $30(0.27)$ & $157(0.26)$ & $146(0.21)$ \\
\hline & Total & 283 & 595 & 322 & 111 & 605 & 706 \\
\hline & Allele frequency $\mathrm{A} / \mathrm{C}$ & $0.55 / 0.45$ & $0.57 / 0.43$ & $0.50 / 0.50$ & $0.51 / 0.49$ & $0.53 / 0.47$ & $0.56 / 0.44$ \\
\hline
\end{tabular}

Figures in parentheses indicate frequencies; $\mathrm{p}$-values $>0.05$ for all allelic and genotypic comparisons; $\mathrm{p}$-values were not corrected for multiple comparisons. 
Table 2: Haplotype association analysis between DYRKI A gene and AD

\begin{tabular}{cccc}
\hline Haplotype block & Haplotype frequency & AD, control frequency & P value \\
\hline ATACCG & 0.329 & $0.347,0.314$ & 0.07 \\
ACGCCA & 0.202 & $0.190,0.211$ & 0.18 \\
ATATCG & 0.154 & $0.152,0.155$ & 0.82 \\
ATACTG & 0.115 & $0.112,0.118$ & 0.61 \\
GTGCCA & 0.109 & $0.107,0.112$ & 0.65 \\
ATACCA & 0.074 & $0.069,0.077$ & 0.43 \\
\hline
\end{tabular}

Haplotype block consists of SNPs: rs I 170 I483, rs2835740, rs I I 37600, rs283576I, rs2835762 and rs2 I54545. Rare haplotypes (total frequency< $0.05)$ were excluded from the analysis. P-values were not corrected for multiple comparisons.

indicated that two haplotypes had significantly different frequencies between $\mathrm{AD}$ and controls. These authors showed that the expression of DYRK1A mRNA was elevated in the hippocampus of AD patients, coinciding with another report of increased DYRK1A immunoreactivity in the frontal cortex, entorhinal cortex and hippocampus of AD patients [4]. All the tagging SNPs analyzed in our study are located in a single block that does not cover the whole gene (captures $86 \%$ of DYRK1A genetic variability), but is the same haplotype block as described by Kimura et al. in their Japanese cohort. It could have been a great interest to identify possible DYRK1A genetic association using tagging SNPs located in haplotype blocks flanking the block illustrated in Figure 1; however, our main objective was to study the most strongly associated SNP rs2835740 (intron 3) of the original paper suggesting DYRK1A as a putative gene causing $\mathrm{AD}[12]$, and, in addition, we genotyped other SNPs in intron 3 (rs11701483, rs1137600 and rs2835761), intron 4 (rs2835762) and intron 10 (rs2154545 and rs8132976). In contrast with the findings of Kimura et al., we did not find any genetic association. Our failure to replicate the main finding of Kimura et al. could be caused by several factors. The possibility of a type 2 error (false-negative) must be taken in account, but we had enough power $(98 \%)$ to detect an odds ratio of 1.5 at disease allele frequencies of approximately 0.15 . Another possibility is genetic heterogeneity between our sample sets and those of the original study. While DYRK1A rs2835740 revealed evidence for association in Japanese samples, this SNP was not associated with AD in our Caucasian sample, and independent replication studies are needed in this gene to verify or refute the finding here and to extend it to other ethnic groups.

\section{Conclusion}

Our negative findings in the Spanish population argue against the hypothesis that DYRK1A genetic variations are causally related to AD risk. Still, additional studies using different sets of patients and control subjects deserve further attention, since supporting evidence for association between DYRK1A gene and AD risk in the Japanese population exists.

\section{Competing interests}

The authors declare that they have no competing interests.

\section{Authors' contributions}

JLVH and ERR performed the genetic studies and reviewed critically the manuscript. PSJ performed the statistical analyses and reviewed critically the manuscript. IM, AP, $\mathrm{AF}$, IS, FV, JB and MJB reviewed critically the manuscript. OC drafted the manuscript and contributed to its final version. All authors read and approved the final manuscript.

\section{Acknowledgements}

The authors thank Weyma Notel's help in Figure I edition. C. SánchezQuintana y S. Curiel del Olmo were involved in the DNA sample collections and genotyping analysis from Santander, We also thank Drs. P. Gil and $P$. Coria for their cooperation in the generation of the casecontrol samples from Madrid, and to A. Martínez-García for technical assistance. This work was made possible by the generous participation of the patients, the control subjects, and their families. This study was supported by grants from FIS (PI080 I39) and CIBERNED (CB06/07/0037).

\section{References}

I. Iqbal K, Liu F, Gong CX, Alonso AC, Grundke-lqbal I: Mechanisms of tau-induced neurodegeneration. Acta Neuropathol 2009, I 1 8:53-69.

2. Woods YL, Cohen P, Becker W, Jakes R, Goedert M, Wang X, Proud $C G$ : The kinase DYRK phosphorylates protein-synthesis initiation factor elF2B $\varepsilon$ at $\operatorname{Ser}^{539}$ and the microtubule-associated protein tau at $\mathrm{Thr}^{212}$ : potential role of DYRK as a glycogen synthase kinase 3-priming kinase. Biochem J 200I, 355:609-I5.

3. Ryoo SR, leong HK, Radnaabazar C, Yoo IJ, Cho HJ, Lee HW, Kim IS, Cheon YH, Ahn YS, Chung SH, Song WJ: DYRKIA-mediated hyperphosphorylation of tau. A functional link between Down syndrome and Alzheimer disease. I Biol Chem 2007, 282:34850-7.

4. Ferrer I, Barrachina M, Puig B, Martínez de Lagrán M, Martí E, Avila J, Dierssen M: Constitutive Dyrk IA is abnormally expressed in Alzheimer disease, Down syndrome, Pick disease, and related transgenic models. Neurobiol Dis 2005, 20:392-400.

5. Wegiel J, Dowjat K, Kaczmarski W, Kuchna I, Nowicki K, Frackowiak J, Kolecka BM, Wegiel J, Silverman WP, Reisberg B, deLeon M, Wisniewski T, Gong CX, Liu F, Adayev T, Chen-Hwang MC, Hwang YW: The role of overexpressed DYRKIA protein in the early onset of neurofibrillary degeneration in Down syndrome. Acta Neuropathol 2008, I l 6:39|-407.

6. Shi J, Zhang T, Zhou C, Chohan MO, Gu X, Wegiel J, Zhou J, Hwang YW, Iqbal K, Grundke-lqbal I, Gong CX, Liu F: Increase dosage of DyrkIA alters alternative splicing factor (ASF)-regulated alternative splicing of tau in Down syndrome. J Biol Chem 2008, 283:28660-9. 
7. Liu F, Liang Z, Wegiel J, Hwang YW, lqbal K, Grundke-lqbal I, Ramakrishna N, Gong CX: Overexpression of DyrkIA contributes to neurofibrillary degeneration in Down syndrome. FASEB J 2008, 22:3224-33.

8. Bertram L, McQueen MB, Mullin K, Blacker D, Tanzi RE: Systematic meta-analyses of Alzheimer disease genetic association studies: the AlzGene database. Nat Genet 2007, 39: 17-23.

9. Feulner TM, Laws SM, Friedrich P, Wagenpfeil S, Wurst SH, Riehle C, Kuhn KA, Krawczak M, Schreiber S, Nikolaus S, Förstl H, Kurz A, Riemenschneider M: Examination of the current top candidate genes for $A D$ in a genome-wide association study. Mol Psychiatry 2009. doi: $10.1038 / \mathrm{mp} .2008 .141$

10. Harold D, Abraham R, Hollingworth P, Sims R, Gerrish A, Hamshere ML, Pahwa JS, Moskvina V, Dowzell K, Williams A, Jones N, Thomas C, Stretton A, Morgan AR, Lovestone S, Powell J, Proitsi P, Lupton MK, Brayne C, Rubinsztein DC, Gill M, Lawlor B, Lynch A, Morgan K, Brown KS, Passmore PA, Craig D, McGuinness B, Todd S, Holmes C, Mann D, Smith AD, Love S, Kehoe PG, Hardy J, Mead S, Fox N, Rossor M, Collinge J, Maier W, Jessen F, Schürmann B, Bussche $H$ van den, Heuser I, Kornhuber J, Wiltfang J, Dichgans M, Frölich L, Hampel H, Hüll M, Rujescu D, Goate AM, Kauwe JS, Cruchaga C, Nowotny P, Morris JC, Mayo K, Sleegers K, Bettens K, Engelborghs S, De Deyn PP, Van Broeckhoven C, Livingston G, Bass NJ, Gurling H, McQuillin A, Gwilliam R, Deloukas P, Al-Chalabi A, Shaw CE, Tsolaki M, Singleton AB, Guerreiro R, Mühleisen TW, Nöthen MM, Moebus S, Jöckel KH, Klopp N, Wichmann HE, Carrasquillo MM, Pankratz VS, Younkin SG, Holmans PA, O'Donovan M, Owen MJ, Williams J: Genomewide association study identifies variants at CLU and PICALM associated with Alzheimer's disease. Nat Genet 2009. 4I:1088-93.

II. Lambert JC, Heath S, Even G, Campion D, Sleegers K, Hiltunen M, Combarros O, Zelenika D, Bullido MJ, Tavernier B, Letenneur L, Bettens K, Berr C, Pasquier F, Fiévet N, Barberger-Gateau P, Engelborghs S, De Deyn P, Mateo I, Franck A, Helisalmi S, Porcellini E, Hanon O, European Alzheimer's Disease Initiative Investigators, de Pancorbo MM, Lendon C, Dufouil C, Jaillard C, Leveillard T, Alvarez V, Bosco P, Mancuso M, Panza F, Nacmias B, Bossù P, Piccardi P, Annoni G, Seripa $D$, Galimberti D, Hannequin D, Licastro F, Soininen H, Ritchie K, Blanché H, Dartigues JF, Tzourio C, Gut I, Van Broeckhoven C, Alpérovitch A, Lathrop M, Amouyel P: Genome-wide association study identifies variants at CLU and CRI associated with Alzheimer's disease. Nat Genet 2009, 4 I: I094-9.

12. Kimura R, Kamino K, Yamamoto M, Nuripa A, Kida T, Kazui H, Hashimoto R, Tanaka T, Kudo T, Yamagata H, Tabara Y, Miki T, Akatsu H, Kosaka K, Funakoshi E, Nishitomi K, Sakaguchi G, Kato A, Hattori H, Uema T, Takeda M: The DYRKIA gene, encoded in chromosome 2 I Down syndrome critical region, bridges between $\beta$ amyloid production and tau phosphorylation in Alzheimer disease. Hum Mol Genet 2007, 16:15-23.

13. McKhaan G, Drachman D, Folstein M, Katzman R, Price D, Stadlan EM: Clinical diagnosis of Alzheimer's disease: report of the NINCDA-ADRDA Work Group under the auspices of Department of Health and Human Services Task Force on Alzheimer's Disease. Neurology 1984, 34:934-44.

\section{Pre-publication history}

The pre-publication history for this paper can be accessed here:

http://www.biomedcentral.com/1471-2350/10/129/pre pub
Publish with Biomed Central and every scientist can read your work free of charge

"BioMed Central will be the most significant development for disseminating the results of biomedical research in our lifetime. "

Sir Paul Nurse, Cancer Research UK

Your research papers will be:

- available free of charge to the entire biomedical community

- peer reviewed and published immediately upon acceptance

- cited in PubMed and archived on PubMed Central

- yours - you keep the copyright
BioMedcentral 